Theories \& Applications, the International Edition

Printed Version : (ISSN 2090-5262)

Online Version : (ISSN 2090-5270)

July 2014, Volume 4, No. 2 Pages (72 - 84)

\title{
The Effectiveness of Combined Defense Performance in Playing Positions in a Number of Handball Defense Formations "An Analytical Study of Men's World Championship Spain ( 2013 )".
}

\author{
Mohamed Ashraf Mohamed Kamal \\ Assistant professor, Faculty of Physical Education for Men - Alexandria University, Egypt. \\ Wafaa Mohamed Abdel-Meged El-Katamy \\ Assistant professor, Faculty of Physical Education for Girls - Alexandria University, Egypt. \\ Amany Hussen Mohamed Abdel-Hamid
}

Lecturer, Faculty of Physical Education for Girls - Alexandria University, Egypt.

\begin{abstract}
This paper aims at identifying the types of combined defense performance in each playing position in the ( $6: 0)$ closed defense formation and the (3:2:1) open defense formation in the Men's World Championship Spain ( 2013 ), and identifying the effectiveness of playing positions in these formations as used by the Egyptian team and comparing it with a number of other teams in the mentioned championship.

The survey-descriptive method was used 19 matches were analyzed, covering different rounds played by France, Denmark, Spain, Slovenia, Croatia, Poland and Egypt, with a total of 4 matches per team.

Results included identifying the types of combined defense performances in each playing position in the ( $6: 0)$ closed defense formation and the (3:2:1) open defense formation. Effectiveness of the Egyptian team was below average in the ( $6: 0$ ) formation, ranking fourth among 6 teams. Effectiveness of the Egyptian team was low in the (3:2:1) open formation, ranking lst.

According to the study results and the statistical analysis, the research team found the most important results are The highest degree of effectiveness in using the ( 6: 0 ) defense formation occurred in the teams of Croatia and Denmark, the low standard of the Egyptian national team in using this formation The team only got the last-but-one rank in the team classification.

The highest degree of effectiveness in using the (3:2:1) defense formation occurred in the teams of Croatia and Slovenia, the low standard of the Egyptian national team in using this defense formation. The team got the last rank of effectiveness in the team classification.

It is recommended to give due consideration to planning training programs based on results of this study and in a manner suitable to players' abilities and skills, while continuously developing and modifying the training program. Training models suggested should also be used by the team in order to upgrade the defense performance level of Egyptian handball teams.
\end{abstract}

Introduction

$\mathrm{T}$ he 21 st century is a time of rapid scientific progress in all fields, and in the field of sports in particular. In the meantime, sport is an indicator of scientific achievement, being a true mirror of the progress made by a nation, Handball occupies a prominent place among sports activities, being a game of competition during which both teams constantly change positions whether these are of defensive or offensive nature. It also requires special abilities to face changes during the match. As a team game, handball is characterized by difficulty of performing offensive and defensive tactics, a performance that depends on a payer's efficiency in utilizing skills during tactical work.
Defense important in handball, among other things, team with good deffence will have a positive psychological effect on the team during the game. (17:10)

A good handball team is one whose players exert efforts to achieve integration between defense lines, employing individual and team skills so that defenders can control the offensive performance of their rivals. According to Mounir Guirgis (2004), it is no longer sufficient to have as the aim of defense preventing the attacker from opening a gap to shoot through and score a goal. Modern defense methods have gone far beyond this to constantly and persistently attempt to dismantle the offensive concepts of the rival team and leading it astray, thus making it easier for the defense team to take possession of the ball and shift to attack. This 
was the starting point of developing defense skills which changed from passive typical defense to a sort of positive defense. $(16: 281)$

Dietrich Spat (2011) suggested that there was an improvement in the recent years in bounce techniques and shifting from attack to defense, Several teams have been using active defense tactics which often start in the rival team's court to thwart their bounce attack, and organize defense in such a way as to attack their dashing attempts from their positions with the aim of forcing them to re-build the attack attempt. (24:248)

In order for the team to perform their defense duties, there must be a basic system comprising all players, through which each player would be able to implement his or her concept of the defense, thus thwarting the attack concept of the rival team, a system called defense formation.

Raphael Wt. (2000) suggests players should move within the defense formation, in rapid momentary movements to maintain the solidarity of the defense wall against all offensive movements. (30)

Hagan Ruckner (1999) adds that in order to make defenders able to prevent the offenders movements and defeat their tactical concept, they should take their correct defensive positions according to the direction of the defender and the ball, the lines playing positions within ea defense formation, Combined defense performances differ from one player to another and one playing position to another, and a player should perform in such a way as to cooperate with his colleagues and help them to perform their duties.(27)

Yasser Dabbour (1997) suggests that skills must be developed based on their tactical use in competitive situations. This would be positively reflected on the effective use of such skills in situations during competition because the competitive situation requires combined skillful performances that have a direct effect on deciding competitive situations. (21:64)

Abdel Aziz Salama (2001) and Amrallah Albusaty (1999) confirm that possessing various forms of motor skills similar to those required during competition gives the player the opportunity to choose the best in most of the actual playing situations and increase his ability to maneuver and carry out tactics in different places and directions. This would help reach speedy performance that is accurate and wellcoordinated. (12:15), (3:161)

Authors of this paper are of the opinion that studying the combined defense performance in the playing positions is particularly important in the training processes so that it can be used with a high degree of effectiveness during the match and so that the team can perform its duties. Mastering such performances by the players is essential to win the game.

Results achieved by the Egyptian Handball team have been deteriorating and the team could not pass preliminary competitions qualifying for world championships. This situation was behind the authors' decision to study the effectiveness of combined defense performance in playing positions in the closed defense formation ( 6:0 ) and the open defense formation (3:2:1) used by the Egyptian National Men's Team, comparing it to a number of international teams that reached advanced positions in the ( 2013 ) World Championship hosted by Spain. The aim was to identify points of weakness in the Egyptian National Team, using the information generated as guidelines in the future preparation of the Egyptian team.

The closed defense formation ( 6:0 ) and the open defense formation (3:2:1) were chosen as subject of this study because the former is one of the major close defense formations and the basis for all other defense formations, and the latter is one of the major open defense formations, (Khaled Hammouda \& Galal Salem (2008) (15: 134) and Kamal Darwish et al., (2002) (9: 156 ), Amany Hussein (1999) (1), Zoran Valdevit et al, (2004) (32), Yasar Savim (2007) (31) and Tarek Rehab (2008) (17).

Identifying the combined defense performances, as applied in actual situations of competition, on the other hand, helps coaches apply such performances in the training process in order to improve tactical defensive performance and upgrade the training process, especially in the case of junior players, as opposed to the traditional method of training used by some coaches to teach skills individually.

\section{Previous studies:}

1. Studies on the analysis of defense work (25), (2), (3), (17) and (6).

2. Studies on defensive skills (13), (11), (28), (14) and (26).

Reference survey of previous studies showed that some of the studies analyzed defense work, while others tackled the skillful and defensive movements, Some also attempted to identify the most effective defense methods and formations in different teams, To the best of the authors' knowledge, none of the previous studies attempted to investigate the combined defense performances for each playing position and the effectiveness of the defensive performance of the Egyptian team, or compare it with that of a number of others international teams through the closed defense formation (6:0 ) and the open defense formation (3:2:1) in the world championship of Spain (2013).

\section{The research aim:}

This research aims to recognizing the effectiveness of the combined defensive performances to the play positions for some defensive formations during world men championship of handball in Spain ( 2013 ) through:

1. Identifying the combined defense performances and the most repeated of each playing position in the closed defense formation ( $6: 0)$ and the open defense formation (3:2:1) in the world championship of handball in Spain, ( 2013 ). 
2. Identifying the effectiveness of the combined defensive performance in the playing positions in the closed defense formation (6:0) and the open defensive formation $(3: 2: 1)$ in world championship of handball in Spain (2013).

3. Comparing the level of effectiveness of the combined defense performance of the national Egyptian team to that of a number of the world's national teams in the closed defense formation ( 6:0 ) and the open defense formation (3:2:1) in the world championship in Spain, ( 2013 ).

\section{Research questions:}

What are the combined defense performances and the most repeated of each playing position in the closed defense formation (6: 0$)$ and the open defense formation (3:2:1) in the world championship of handball in Spain, ( 2013 )?

What are the effectiveness of the combined defensive performance in the playing positions in the closed defense formation (6:0) and the open defensive formation (3:2:1) in world championship of handball in Spain (2013)?
What are the level of effectiveness of the combined defense performance of the national Egyptian team compared to that of a number of the world's national teams in the closed defense formation ( 6:0 ) and the open defense formation (3:2:1) in the world championship in Spain ( 2013 )?

\section{Research procedures}

\section{Method}

The survey- descriptive method was used, being suitable for this type of study.

Sample

The sample was of the non-random stratified type and consisted of ( 19 ) opening and final matches played by the teams of France, Denmark, Spain, Slovenia, Croatia, Poland and Egypt, comprising (4) matches by every team and representing the different schools of international handball, besides being among the best teams in skillful and tactical performance.

Table (1)

Research sample

\begin{tabular}{|c|c|c|c|c|c|}
\hline \multicolumn{7}{|c|}{ Matches studied } \\
\hline Round & Result & Match & Round & Result & Match \\
\hline First round & $25-24$ & Slovenia X Poland & Eighth final & $\mathbf{2 6 - 3 1}$ & Egypt X Slovenia \\
\hline First round & $31-27$ & Denmark X Russia & First round & $\mathbf{2 4 - 2 9}$ & Egypt X Spain \\
\hline First round & $\mathbf{3 6 - 2 8}$ & Denmark X Iceland & First round & $\mathbf{2 3 - 3 2}$ & Egypt X Hungary \\
\hline First round & $\mathbf{2 5 - 2 4}$ & Poland X Serbia & First round & $\mathbf{2 4 - 2 4}$ & Egypt X Algeria \\
\hline Eighth final & $\mathbf{1 9 - 2 7}$ & Poland X Hungary & Quarterfinals & $\mathbf{3 0 - 2 3}$ & Croatia X France \\
\hline First round & $33-25$ & Poland X Korea & First round & $\mathbf{2 7 - 2 5}$ & Croatia X Spain \\
\hline Eighth final & $\mathbf{3 0 - 2 8}$ & France X Iceland & Semi-final & $\mathbf{2 4 - 3 0}$ & Croatia X Denmark \\
\hline First round & $\mathbf{3 0 - 3 2}$ & France X Germany & Third \& fourth places & $\mathbf{3 1 - 2 6}$ & Croatia X Slovenia \\
\hline First round & $\mathbf{3 0 - 2 7}$ & France X Tunisia & Semi-final & $\mathbf{2 6 - 2 2}$ & Spain X Slovenia \\
\hline & & & Final & $35-19$ & Spain X Denmark \\
\hline
\end{tabular}

\section{Data Collecting Tools}

Regulated observation was used as a data collecting tool through:

- Compact discs with the matches studied saved on them.

- Registration form designed by authors of the paper. Attachment ( )

- Interviews with experts to ask for their opinions about the registration form and make changes as recommended.

- Dart Fish analysis program.

- Computer.
Steps of Building up the Data Collecting Form

The pilot study was conducted in the period 1/10/2012 $15 / 12 / 2012$ with the aim of reaching the final data collecting form.

The pilot study included the following:

1. An analysis of reference works on defense performances, as a referential framework in handball such as Yasser Dabour (1996) (20), Verner Vick et al. (1997) (18), Galal Kamal Salem (2002) (7), Kamal Abd El-Hameed and Muhammad Sobhy Hassanein (2002) (8), Khaled Hamouda and Galal Salem (2008) (15).

2. An analysis of previous field studies and research on the defensive side, such as the study of Wafaa Abd 
El-Mageed (2005) (19), Marwan Mustafa Ragab (2009) (10), Muhammad Ashraf (2011) (14), Ekramy Muhammad (2012) (6) in order to identify the research variables in the registration form and submitting it to experts (Attachment) ( 1 ) through interviews to ask for their opinions about deleting or adding any variable in the light of research objectives to ensure the validity of the form which included the following variables:

- The defense formation ( 6:0 ) and players' positions (right defense center, left defense center, right back defense, left back defense, right defense and left defense wing)

- The defense formation (3:2:1) and players' positions (front defense center, back defense center, right back defense, left back defense, right defense and left defense wing).

- Identifying the combined defense performances of playing positions and their repetition.

- Effectiveness (success represented in possessing the ball or getting a free throw) (failure represented in scoring a goal by the opponent team or getting a $7 \mathrm{~m}$ shot ).

- Experts agreed unanimously on the validity of the form to describe the variables to be observed.

\section{Form Reliability}

Reliability of the form was verified by conducting the first measurement on the world cup match in Sweden (2011) between France and Germany, then repeating the measurement with the same conditions one week after the first measurement and the coefficient of agreement was calculated and found to be $92 \%$ which indicates a high factor of form reliability.

\section{The Basic Study}

1. After verification of scientific coefficients of the form, the basic study was conducted in the period Result Presentation and Discussion

Result Presentation:
$15 / 2 / 2013$ - 15/3/2013 to analyze 19 matches of the world cup championship in Spain ( 2013 ), using the Dart Fish program to find the combined defense performance of each of the playing positions in the closed defense formation ( $6: 0$ ) and the open defense formation (3:2:1). The defense performance of players was observed during the ball handling by the attacking team both in building up and finishing the attack from positions.

2. The effectiveness of the defense performance of each of the playing positions in the closed defense formation ( $6: 0$ ) and the open defense formation (3:2:1) was defined. Success means possessing the ball or winning a free throw, whereas failure means scoring a goal or getting a $7 \mathrm{~m}$ shot. Level of effectiveness was identified through a criterion to measure the actual level through percentages obtained by the defense position of each theme. The highest percentage obtained the highest score, the lower the percentage, the lower and the level of effectiveness.

3. On completion of observation repetitions of performance of the two defense center positions (right and left) were integrated in the formation ( 6:0 ), and the repetitions of performance of the two back defense positions (right and left) and the defense wing (right and left) were integrated in the formations ( 6:0) and (3:2:1) because of the similarity in motor performance of these positions.

4. Data was filled in on the form in order to proceed with statistic treatments.

\section{$\underline{\text { Statistical Treatments }}$}

- Percentage

- Coefficient of reliability and objectivity

- Relative importance

Table (2)

Percentage of the Combined Defense Performance of the Positions of Defense Center (Right and Left) in the Closed Defense Formation ( 6:0 )

\begin{tabular}{|c|c|c|c|}
\hline No & the Combined Defensive Performance & Repetitions & $\%$ \\
\hline 1 & moving aside, attacking and obstructing shooting & 69 & 17.468 \\
\hline 2 & Moving forwards and obstructing passing & 56 & 14.177 \\
\hline 3 & Moving aside, attacking and obstructing passing & 44 & 11.139 \\
\hline 4 & Moving forwards, attacking and blocking wall & 41 & 10.379 \\
\hline 5 & Moving aside and blocking wall & 38 & $\mathbf{9 . 6 2 0}$ \\
\hline 6 & Moving forwards and obstructing shooting & 35 & $\mathbf{8 . 8 6 0}$ \\
\hline 7 & Diagonal forward movement, attacking, opposing faint movement and & 34 & $\mathbf{8 . 6 0 7}$ \\
\hline
\end{tabular}




\begin{tabular}{|c|c|c|c|}
\hline No & the Combined Defensive Performance & Repetitions & $\%$ \\
\hline 8 & $\begin{array}{c}\text { Avoiding obstruction, diagonal defense movement forwards, stopping to attack } \\
\text { and obstructing faint movement }\end{array}$ & 33 & 8.354 \\
\hline 9 & Moving aside, attacking and obstructing faint movement & 25 & 6.329 \\
\hline 10 & Moving aside and defending on follow up movement after obstruction & 20 & 5.063 \\
\hline Total & & 259 & 100 \\
\hline
\end{tabular}

Table (3) shows that repetition of combined defense performance varies between $17.468 \%$ and $5.063 \%$. The most repeated performances were those finishing with obstructing shooting and obstructing passing which occupied first to sixth ranks with percentages varying between $17.468 \%$ and $8.860 \%$.

Table (3)

Percentage of the Combined Defense Performance of the Positions of Back Defense (Right and Left) in the Closed Defense Formation ( $6: 0$ )

\begin{tabular}{|c|c|c|c|}
\hline No & The Combined Defensive Performance & Repetitions & $\%$ \\
\hline 1 & Moving forward, attacking and obstructing shooting & 68 & 16.464 \\
\hline 2 & Moving aside, attacking and obstructing shooting & $\mathbf{5 5}$ & 11.380 \\
\hline 3 & $\begin{array}{c}\text { Avoiding blocking, moving aside and moving forward with a stopping to } \\
\text { attack and obstruct shooting }\end{array}$ & 47 & 10.411 \\
\hline 4 & Diagonal forward movement, attacking, opposing faint movement & 43 & 8.232 \\
\hline 5 & Moving aside, attacking and obstructing passing & 34 & 7.263 \\
\hline 6 & Diagonal movement forward, moving aside, stopping and attacking with & 30 & 6.779 \\
\hline 7 & Moving forward and blocking wall & 28 & 6.053 \\
\hline 8 & Diagonal movement forward, movement backwards and avoiding & 25 & 5.569 \\
\hline 9 & blocking while attacking an opposing faint movement & 23 & 5.326 \\
\hline 10 & Moving forwards while attacking and obstructing passing & 22 & 4.842 \\
\hline 11 & Moving aside and defending on follow up ovement after obstruction & 20 & 4.358 \\
\hline 12 & Moving aside and a blocking wall & 18 & 100 \\
\hline Total & & 413 & \\
\hline
\end{tabular}

Table (4) shows that repetition of combined defense performance varies between $16.464 \%$ and $(4.358 \%)$, The most repeated performances were those finishing with obstructing shooting, and which occupied first to third ranks with percentages varying between $(16.464 \%)$ and $(11.380 \%)$.

Table (4)

Percentage of the Combined Defense Performance of the Positions of Defense Wing

(Right and Left) of the Closed Defense Formation ( 6:0 )

\begin{tabular}{|c|c|c|c|}
\hline NO & The complex defensive performance & Repetition & $\%$ \\
\hline 1 & Running on the circle and stopping to attack while obstructing shooting & 21 & 20.00 \\
\hline 2 & Diagonal movement forward, moving backwards and obstructing shooting & 18 & 17.142 \\
\hline 3 & Diagonal movement forward, moving backwards and obstructing passing & 16 & 15.238 \\
\hline 4 & Moving aside, stopping to attack and opposing faint movement & 14 & 13.333 \\
\hline 5 & Moving aside, stopping to attack and obstructing shooting & 13 & 12.380 \\
\hline 6 & Running on the circle and stopping to attack while obstructing passing & 11 & 10.476 \\
\hline 7 & Moving aside, stopping to attack and obstructing passing & 7 & 6.666 \\
\hline 8 & Moving aside and defending on follow up movement after obstruction & 5 & 4.761 \\
\hline Total & & 105 & 100 \\
\hline
\end{tabular}

Table (5) shows that repetition of combined defense performance varies between $(20.00 \%)$ and $(4.761 \%)$, The most repeated performances were those finishing with obstructing shooting, obstructing passing and opposing faint movement which occupied first to sixth ranks with percentages varying between (20.00\%) and (10.476\%). 
Table (5)

Percentage of Success and Failure of Combined Defense Performance in the Positions of Closed Defense Formation ( 6:0 ) of All Teams Studied

\begin{tabular}{|c|c|c|c|c|c|c|}
\hline \multirow{2}{*}{$\begin{array}{c}\text { Repetition \& } \\
\text { Percentage }\end{array}$} & $\begin{array}{c}\text { Right } \\
\text { Defense } \\
\text { Center }\end{array}$ & $\begin{array}{c}\text { Left Defense } \\
\text { Center }\end{array}$ & $\begin{array}{c}\text { Right Back } \\
\text { Defense }\end{array}$ & $\begin{array}{c}\text { Left Back } \\
\text { Defense }\end{array}$ & $\begin{array}{c}\text { Right } \\
\text { Defense } \\
\text { Wing }\end{array}$ & $\begin{array}{c}\text { Left Defense } \\
\text { Wing }\end{array}$ \\
\hline Success & 132 & 98 & 114 & 116 & 25 & 19 \\
\hline$\%$ & 67.35 & 49.25 & 50.67 & 61.70 & 43.86 & 39.58 \\
\hline Failure & 64 & 101 & 111 & 72 & 32 & 29 \\
\hline Percentage\% & 32.65 & 50.75 & 49.33 & 38.30 & 56.14 & 60.42 \\
\hline Total & 196 & 199 & 225 & 188 & 57 & 48 \\
\hline
\end{tabular}

Table (6) shows that the position with the highest degree of movement was the right back defense, with a repetition of ( 225 ) times, the position with the lowest degree of movement was the left defense wing with a repetition of 48 times. It also shows that the right defense center $(67.35 \%)$, the left back defense $(61.70 \%)$, and the right back defense $(50.67 \%)$ respectively were the most successful. Failure percentage was higher than successful percentage in each of the left defense wing (60.42\%), the right defense wing $(56.14 \%)$ and the left defense center $(50.75 \%)$.

Table (6)

Percentage of Success and Failure of the Combined Defense Performance of the Positions in the Closed Defense Formation ( 6:0 ) of Each Team Studied

\begin{tabular}{|c|c|c|c|c|c|c|c|c|c|c|c|c|c|c|c|c|c|c|c|c|c|c|c|c|}
\hline 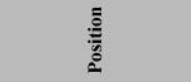 & $\stackrel{\text { ğ }}{\underline{z}}$ & $\therefore$ & 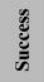 & $\therefore$ & 竞 & $\stackrel{0}{2}$ & 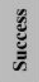 & $\therefore$ & 总 & $\therefore$ & $\begin{array}{l}\hat{E} \\
\text { क् }\end{array}$ & $\therefore$ & 气를 & $\therefore$ & $\begin{array}{l}\text { है } \\
\text { है }\end{array}$ & $\therefore$ & 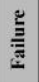 & $\therefore$ & 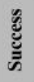 & $\stackrel{0}{0}$ & $\frac{气}{\bar{E}}$ & $\AA^{0}$ & 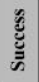 & $\partial^{\circ}$ \\
\hline Right defense center & 9 & 24.32 & 28 & 75.68 & 16 & 39.02 & 25 & 60.98 & 16 & 45.27 & 19 & 54.28 & 5 & 17.86 & 23 & 82.14 & 6 & 27 & 16 & 72.73 & 12 & 36.36 & 21 & 63.64 \\
\hline Right back defense & 16 & 43.25 & 21 & 56.75 & 18 & 50 & 18 & 50 & 23 & 45.10 & 28 & 54.90 & 16 & 47.06 & 18 & 52.94 & 13 & 52.17 & 18 & 58.06 & 25 & 69.44 & 11 & 30.56 \\
\hline Left back defense & 8 & 32 & 17 & 68 & 6 & 25 & 18 & 75 & 8 & 21.05 & 30 & 78.95 & 16 & 48.48 & 17 & 51.52 & 14 & 41.94 & 23 & 62.16 & 20 & 64.52 & 11 & 35.48 \\
\hline Total & & & 100 & 19.84 & & & 78 & 15.47 & & & 96 & 19.04 & & & 79 & 15.67 & & 71.43 & 74 & 14.68 & & & 77 & 15.27 \\
\hline
\end{tabular}

Table (7) shows that the right defense center was more effective in the closed defense formation ( 6:0 ) in the teams of Poland $(82.14 \%)$ followed by Croatia $(75.68 \%)$ and Slovenia $(72.73 \%)$. The left defense center was more effective in the teams of Poland $(72.00 \%)$, followed by Egypt $(57.50 \%)$, then Croatia (54.54\%). The right back position was more effective in the team of Slovenia $(58.06 \%)$, followed by Croatia $(56.75 \%)$ then Denmark
$(54.90 \%)$. The effectiveness of the left back defense was $78.95 \%$ in the team of Denmark, followed by Spain $(75 \%)$, then Croatia $(68 \%)$. The percentage of effectiveness of the right defense wing was above average in the team of Croatia $(55.56 \%)$, followed by Egypt (53.85\%), then Poland (50\%). The left defense wing was more effective in the team of Croatia $(83.33 \%)$ followed by Spain $(44.44 \%)$. 
Tale (7)

The effectiveness of the combined defense performance of positions in the closed defense formation $(6: 0)$ in the teams studied

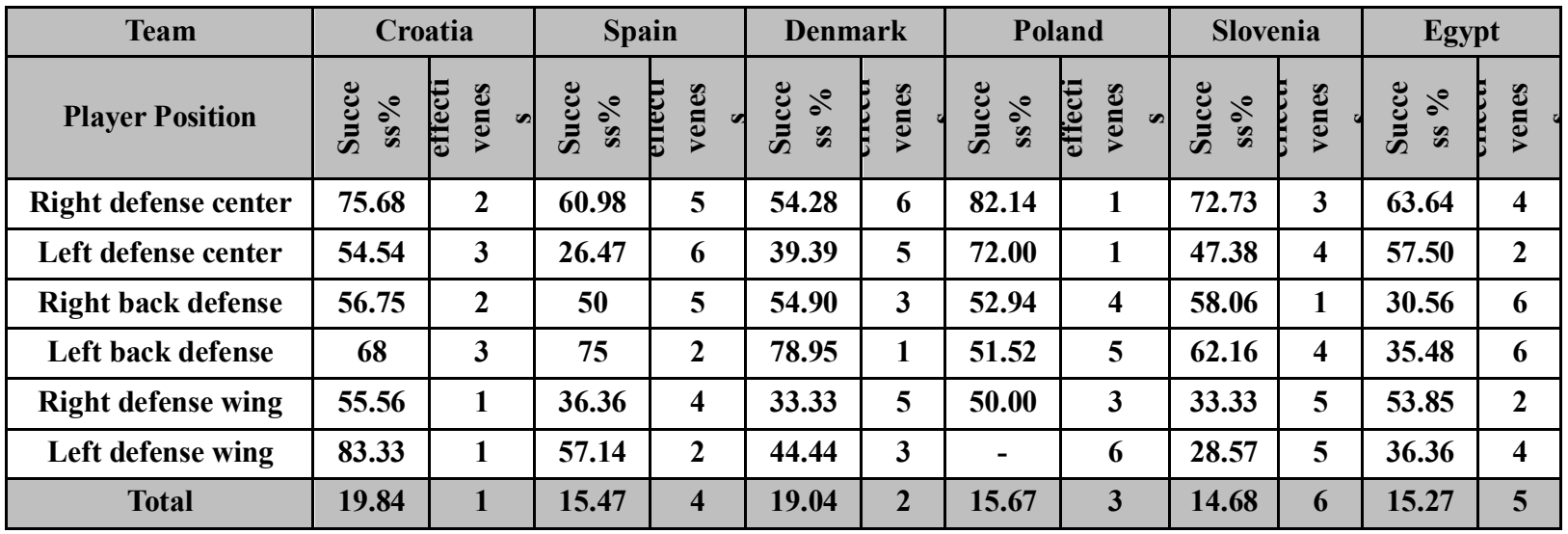

Table (8) shows that the effectiveness of combined defense performance of playing positions in the defense formation ( 6: 0 ) was in its first level in the right and left defense center in the team of Poland, the left back defense in the team of
Denmark, the right back defense in the team of Slovenia, the right and left defense wings in the team of Croatia, while the Egyptian national team did not attain the highest level of effectiveness in any of the defense playing position.

Table (8)

Percentage of the Combined Defense Performance of the Position of the Front Defense Center in the Open Defense Formation (3:2:1).

\begin{tabular}{|c|c|c|c|}
\hline No & The combined defense performance & Repetition & $\%$ \\
\hline 1 & Moving forwards then aside while defending on blocking & 30 & 25.00 \\
\hline 2 & Avoiding blocking and opposing faint movement or obstructing shooting & 27 & 22.5 \\
\hline 3 & Moving forwards then obstructing shooting & 22 & 18.333 \\
\hline 4 & Moving forwards then obstructing passing & 21 & 17.5 \\
\hline 5 & Moving aside then stopping to attack and oppose faint movement & $\mathbf{2 0}$ & 16.666 \\
\hline Total & & 120 & 100 \\
\hline
\end{tabular}

Table (9) shows that the repetition of the combined defense performance varied between ( $25.00 \%$ ) and ( $16.666 \%)$, performance most repeated were those ending with defending on blocking and obstructing shooting which occupied the first and second ranks with percentages of $(25.00 \%)$ and $(22.5 \%)$..

Table (9)

Percentage of the Combined Defense Performance of the Positions of the Back Defense Center in the Open Defense Formation (3:2:1).

\begin{tabular}{|c|c|c|c|}
\hline No & The combined defense performance & Repetition & $\%$ \\
\hline 1 & Avoiding blocking then opposing faint movement or obstructing shooting & 67 & 43.791 \\
\hline 2 & Moving aside then defending on follow up after blocking & 36 & 23.529 \\
\hline 3 & Moving aside then stopping to attack and blocking wall by jumping & 31 & 20.262 \\
\hline 4 & Diagonal movement backwards then obstructing passing & 19 & 12.418 \\
\hline Total & & 153 & 100 \\
\hline
\end{tabular}

Table (10) shows that the repetition of the combined defense performance varied between $(43.791 \%)$ and ( $12.418 \%)$, The combined defense performance most repeated was avoiding blocking then opposing faint movement or obstructing shooting with a percentage of (
$43.791 \%$ ), followed in close percentages by the performances ending with a follow up after blocking and blocking wall by jumping with percentages varying between $(23.529 \%)$ and (20.262\%).. 
Table (10)

Percentage of the Combined Defense Performance of the Positions of the Right and Left Back Defense in the Open Defense Formation (3:2:1)

\begin{tabular}{|c|c|c|c|}
\hline No & The combined defense performance & Repetition & $\%$ \\
\hline 1 & Moving forwards while attacking then obstructing shooting & 95 & 26.243 \\
\hline 2 & Moving forwards while attacking then obstructing passing & 72 & 19.889 \\
\hline 3 & $\begin{array}{c}\text { Avoiding blocking then diagonal movement forwards while attacking and } \\
\text { opposing faint movement }\end{array}$ & 70 & 19.337 \\
\hline 4 & $\begin{array}{c}\text { Diagonal movement forwards then stopping to attack and opposing faint } \\
\text { movement }\end{array}$ & 64 & 14.679 \\
\hline 5 & $\begin{array}{l}\text { Moving aside then moving backwards while defending on a follow up movement } \\
\text { after blocking }\end{array}$ & 61 & 16.850 \\
\hline Total & & 362 & 100 \\
\hline
\end{tabular}

Table (11) shows that the repetition of the combined defense performance varied between ( $26.243 \%$ ) and ( $16.850 \%$ ), The combined defense performance most repeated was that ending with obstructing shooting with a percentage of ( $26.243 \%)$, followed by all other performances in close percentages varying between $(19.889 \%)$ and $(16.850 \%)$

Table (11)

Percentage of the Combined Defense Performance of the Positions of the Right and Left Defense Wing in the Open Defense Formation (3:2:1)

\begin{tabular}{|c|c|c|c|}
\hline No & The combined defense performance & Repetition & $\%$ \\
\hline 1 & $\begin{array}{c}\text { Diagonal movement forwards then stopping to attack then obstructing } \\
\text { shooting }\end{array}$ & 30 & 22.727 \\
\hline 2 & $\begin{array}{c}\text { Diagonal movement forwards then stopping to attack then obstructing } \\
\text { passing }\end{array}$ & 25 & 18.939 \\
\hline 3 & $\begin{array}{c}\text { Diagonal movement forwards then stopping to attack then opposing faint } \\
\text { movement }\end{array}$ & 22 & 16.666 \\
\hline 4 & Moving aside then opposing faint movement and pushing out & 20 & 15.151 \\
\hline 5 & $\begin{array}{l}\text { Diagonal movement forwards then stopping to attack then defending on } \\
\text { a follow up movement after blocking }\end{array}$ & 19 & 14.393 \\
\hline 6 & Moving aside then defending on a follow up movement after blocking & 16 & 12.121 \\
\hline Total & & 132 & 100 \\
\hline
\end{tabular}

Table (12) shows that the repetition of the combined defense performance varied between( $22.727 \%$ ) and $(12.121 \%)$, The combined defense performance most repeated were those ending with obstructing shooting and passing and opposing faint movement, which occupied the first two third ranks with percentages varying between $(22.727 \%)$ and $(16.666 \%)$. 
Table (12)

Percentage of Success and Failure of the Combined Defense Performance in the Positions of Open Defense Formation (3:2:1) of All Teams Studied

\begin{tabular}{|c|c|c|c|c|c|c|}
\hline \multirow{2}{*}{$\begin{array}{c}\text { Repetition } \\
\begin{array}{c}\text { \& } \\
\text { Percentage }\end{array}\end{array}$} & $\begin{array}{c}\text { Front } \\
\text { Defense } \\
\text { Center }\end{array}$ & $\begin{array}{c}\text { Back } \\
\text { Defense } \\
\text { Center }\end{array}$ & $\begin{array}{c}\text { Right Back } \\
\text { Defense }\end{array}$ & $\begin{array}{c}\text { Left Back } \\
\text { Defense }\end{array}$ & $\begin{array}{c}\text { Right } \\
\text { Defense } \\
\text { Wing }\end{array}$ & $\begin{array}{c}\text { Left Defense } \\
\text { Wing }\end{array}$ \\
\hline Success & 81 & 71 & 106 & 124 & 43 & 18 \\
\hline$\%$ & 67.50 & 46.41 & 58.56 & 68.51 & 48.86 & 40.91 \\
\hline Failure & 39 & 82 & 75 & 57 & 45 & 26 \\
\hline$\%$ & 32.50 & 53.59 & 41.44 & 31.49 & 51.14 & 59.09 \\
\hline Total & 120 & 153 & 181 & 181 & 88 & 44 \\
\hline$\%$ & 100 & 100 & 100 & 100 & 100 & 100 \\
\hline
\end{tabular}

Table (13) shows that the position with the highest degree of movement was the right and left back defense, with a repetition of (181) times. The position with the lowest degree of movement was the left defense wing with a repetition of (44) times, Success percentages were higher than failure percentages in the defense movements of the left back defense $(68.51 \%)$, the front defense center $(67.50 \%)$ and the right back defense $(58.56 \%)$ respectively, Percentage of failure was higher than percentage of success for the left defense wing (59.09\%), back defense center $(53.59 \%)$ and the right defense wing $(51.14 \%)$ respectively

Table (14)

Percentage of Success and Failure of the Combined Defense Performance in the Positions of Open Defense Formation (3:2:1) of Each Team Studied

\begin{tabular}{|c|c|c|c|c|c|c|c|c|c|c|c|c|c|c|c|c|c|c|c|c|c|c|c|c|c|}
\hline \multirow[b]{2}{*}{$\begin{array}{c}\text { Team } \\
\text { Position }\end{array}$} & \multicolumn{5}{|c|}{ Spain } & \multicolumn{5}{|c|}{ France } & \multicolumn{5}{|c|}{ Croatia } & \multicolumn{5}{|c|}{ Slovenia } & \multicolumn{5}{|c|}{ Egypt } \\
\hline & 氖 & $\therefore$ & $\begin{array}{l}\text { है: } \\
\text { ڤ̆ }\end{array}$ & $\therefore$ & 递 & 於 & $\therefore$ & $\begin{array}{l}\mathscr{E} \\
\tilde{E} \\
\bar{E}\end{array}$ & $\therefore$ & 起 है & 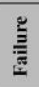 & $\therefore$ & है: & $\therefore$ & 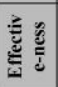 & 竞 & $\therefore$ & है & $\therefore$ & 这 & 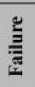 & $\therefore$ & है & $\therefore$ & 站 \\
\hline 产竞 & 17 & 63.00 & 10 & 37 & 5 & 6 & 22.22 & 21 & 77.78 & 3 & 4 & 19.05 & 17 & 80.95 & 2 & 4 & 17.40 & 17 & 82.60 & 1 & 8 & 36.36 & 14 & 63.64 & 4 \\
\hline 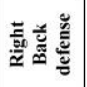 & 22 & 68.75 & 10 & 31.25 & 5 & 6 & 20.69 & 23 & 79.31 & 1 & 12 & 23.07 & 40 & 76.93 & 2 & 14 & 40.00 & 21 & 60.00 & 3 & 21 & 63.64 & 12 & 36.36 & 4 \\
\hline 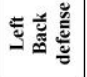 & 8 & 33.33 & 16 & 66.66 & 3 & 15 & 35.71 & 27 & 64.29 & 4 & 10 & 23.26 & 33 & 76.74 & 1 & 11 & 27.50 & 29 & 72.50 & 2 & 13 & 40.62 & 19 & 59.38 & 5 \\
\hline 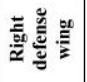 & 6 & 75.00 & 2 & 25.00 & 4 & 4 & 57.15 & 3 & 42.85 & 2 & 7 & 77.78 & 2 & 22.22 & 5 & 3 & 27.27 & 8 & 72.73 & 1 & 6 & 66.67 & 3 & 33.33 & 3 \\
\hline इूँّ & 73 & 52.09 & 65 & 14.67 & 4 & 60 & 37.50 & 100 & 22.57 & 3 & 62 & 36.47 & 108 & 24.37 & 1 & 59 & 35.54 & 107 & 24.15 & 2 & 70 & 52.63 & 63 & 14.22 & 5 \\
\hline
\end{tabular}

Table (14) shows that the right defense center was more effective in the open defense formation $(3: 2: 1)$ in the teams of Slovenia $(82.60 \%)$ followed by Croatia $(80.95 \%)$ then France $(77.78 \%)$, The back defense center was more effective in the team of Spain $(68.57 \%)$, followed by France (53.12\%), then Egypt $(46.15 \%)$, The right back defense was more effective in the team of France $(79.31 \%)$, followed by Croatia $(76.93 \%)$ then Slovenia $(60.00 \%)$, The left back defense was the most effective in the team of Croatia $(76.74 \%)$, followed by Slovenia $(72.50 \%)$, Spain $(66.66 \%)$ and France (64.29\%), The right and left defense wings were more effective in the team of Slovenia (79.31\%) and $(72.73 \%)$ respectively, followed with a wide difference by the team of France $(39.13 \%)$ and $(42.85 \%)$.

The table also shows that the effectiveness of playing positions was in its first level for the front defense center, right defense wing and left defense wing in the team of Slovenia, and the back defense center in the team of Spain, and the right back defense in the team of France, the left back defense in the team of Croatia. The same table shows that the Egyptian national team attained the lowest level of effectiveness in the total of the scores of effectiveness. 


\section{Result discussion}

\section{The ( 6:0 ) defense formation}

Results of tables ( 3), (4) and (5) show that the number of combined defense performances in the right and left defense center position was (10), for the right and left back defense was (12), for the right and left defense wings was ( 8 ) in the defense formation ( 6:0 ). Repetitions of these performances varied, reflecting the types of performances carried out in the playing positions during the matches due to the nature of the changing situations of the competition. This was stressed by Amrallah Albussaty and Muhammad Keshk (2000) who suggested that the variation in the quantity of combined performances and their finishing within the playing positions and lines proves their importance and the necessity of assigning a place for them in the training programs, and training players on them in an early time according to the nature of the match $(4: 30)$

Results of the previous tables show that the most repeated performances in all positions were performances ending with obstructing shooting or obstructing passing, which occupied the first, second and third ranks. This shows the positive nature of the defense in the different playing positions, which is in conformity with results reached by Ekramy Muhammad Hamza (2012) (6) and Dietrich Spat (2009) (23) who suggested that the performances most used were those of attacking the course of the player possessing the ball in most playing methods, with the aim of anticipating the mental ability of the attacker and aborting his offensive effectiveness.

Table( 6 ) shows that the right back defense had the highest degree of movement with a repetition of ( 225 ), followed by the left defense center with a repetition of ( 199 ), then the right defense center with a repetition of (196), The authors attribute this to the fact that defense positions that have the highest degree of movement are those which receive the greatest defense burden because they are responsible for the middle area of the court, and the higher percentage attained by the right back defense position which is higher than that of other positions in view of the fact that most teams concentrate on the left back to finish the attacks.

Repetition of movement of the right defense wing (57) and the left defense wing (48) was the least because of the playing style of the wing defenders in this formation where the wing attacking players are pressed so that they should not receive the ball thus attacks and attempts to finish by the wings are reduced.

These results agree with results reached by Kamal Darweesh and others (1999) who suggested that movements of wing players in the closed defense formation ( 6:0 ) are pressing and sticking to prevent the ball from reaching attackers in the wings and force players of the attacking team to perform passing and receiving in the back line thus reducing opportunities of carrying out their tactical concept (9:57).

The table also shows that the right defense center was the most effective position with a success percentage of (
$67.35 \%$ ) that led to aborting the offensive concept of the opponent because coaches usually are keen to having a player to defend this position who is able to cover the left back attacker and the playmaker. The excellence of the teams studied is attributed to the fact that they are amongst the highest level handball teams. Having tall players able to shoot from a long distance from the $9 \mathrm{~m}$ line caused the coach to seek a defense player who is excellent in carrying out defense performances so that he can face the danger of the attacker and abort the continuous attacks.

Tables ( 7 ) and ( 8 ) show that the highest degree of effectiveness in using the defense formation ( 6:0 ) lay with the teams of Croatia and Denmark. This agrees with the results of the study by Zoran Valdevit et al. (2004) (32) which indicate defense the efficiency of the two teams in defending using the (6:0) formation. Effectiveness of the playing positions in the defense of the Egyptian team using the (6:0) formation was high in the left defense center and the right defense wing positions where effectiveness was in its second level next to teams of Poland and Croatia respectively, whereas effectiveness decreased for the right defense center and the left defense wing positions, where it was in the fourth level. The right back defense and the left back defense positions were in the lowest level of effectiveness despite the defensive importance of these two positions of defense for the attacking backs.

These results show the low level of the Egyptian national team defense and the ability of the opponent teams to defeat the defense of the Egyptian national team.

Authors of this paper are of the opinion that one of the defects of the (6:0) closed defense formation is that it can be defeated through long distance shooting from the back positions of the attacking players in view of the high degree of effectiveness of the left defense center position, followed by the right defense center position which came next to it with a moderate percentage in the defense of the Egyptian team, back attackers of the rival teams chose to shoot from the right and left back positions and avoiding shooting from the playmaker position

\section{The $(3: 2: 1)$ defense formation}

Results of tables (9), (10), (11) and ( 12 ) show that the number of the combined defense performances of the two front defense center positions was ( 5), the number of the combined defense performances of the two back defense center positions was( 4 ), the number of the combined defense performances of the two back defense positions (right and left) was (5), the number of the combined defense performances of the two defense wing positions (right and left) was 6 in the (3:2:1) open defense formation.

It is obvious that the combined defense performances of the different playing positions in the (3:2:1) open defense formation were characterized by different movements, opposing faint movement, defense on blocking and obstructing shots, This indicates the style of offensive performance against the open defense formations, a performance which includes blocking and faint movements 
to make use of the wide inter-distances and the attempts to break through. Also clear is the small differences between percentages of he highest and lowest performances repeated, an indication of the importance of all movements alike. Authors of this paper are of the opinion that players in the defense centers (front and back) should be intelligent, and able to anticipate, read the court and observe the defense distances. This was stressed by Pant Johanson et al (2009) and Dietrich Spat (2009) who suggested that players in such positions should possess special abilities to face offensive work, avoid the blocking and make use of the situations to lead the attack astray. (29:6), (23:36)

Results of Table ( 13) show that the defense positions with the highest degree of movement in the $(3: 2: 1)$ defense formation were the right and left back defense positions, with a repetition of (181) times each, followed by the back defense center position with a repetition of (153), This is attributed by the authors to the nature of work within the (3:2:1) defense formation, which forces attackers to move as suitable to the performance style within the defense formation. One duty of the front defense center in the (3:2:1) defense formation is pressing the playmaker of the attacking team. This will entail more movement by the two, right and left, attackers, and consequently by the two back defense players. An advantage of this defense formation is that it creates a continuous pressure on the (2) attacking players. The defense players should have a good knowledge of tactics and the ability to continuously move during the attack build up, so that they can obstruct the passing route or change the timing and rhythm of play, thus reducing the effectiveness of back line players and the risk represented by the playmaker.

Results also show that the most effective performances were carried out by the left back defense, front defense center and right back defense. Percentage of success of defense movements was higher than percentage of failure. These positions represent the front line players of defense, a fact which illustrates the style of work within this formation. They seek to reduce the movement of back attackers on the $9 \mathrm{~m}$ line, thus reducing the risk of shooting by these attackers and preventing the ball from reaching the attacker near the circle. This is in line with results reached by Khaled Hammouda and Galal Salem (2008) who say that the (3:2:1) defense formation restricts the back attackers' movement on the $9 \mathrm{~m}$ line and speed of their progress towards the goal area, thus reducing the danger of their shooting. (10:424)

The same table shows that the percentage of failure was higher than the percentage of success in he left defense wing position, the back defense center, followed by the right defense wing, which form the back defense line. This is the major defect of the $(3: 2: 1)$ open defense formation. The distances between the defenders are great and needs fast movement to cover the distances. This is in line with results reached by Khaled Hammouda and Galal Salem (2008) who say that this formation gives the opportunity to the wing attackers to move in a wide range void of defensive control. $(10: 424)$
Results of Table (14) show that the effectiveness of playing positions in the Egyptian national team in the $(3: 2: 1)$ defense formation was average for the back defense center and the left defense wing, and below average for the front defense center, the right back defense and the right defense wing. Effectiveness was in its lowest level for the left back defense position.

The above-mentioned results indicate that the effectiveness of the combined defense performances of the playing positions in the (3:2:1) defense formation of the Egyptian national team was moderate, below average and low. This gives superiority to the rival teams over this defense formation used by the Egyptian team. The (3:2:1) open defense formation is a defense formation that demonstrates the positive attitude of the defense player in every moment of defense so that defense players can maintain the coherence of the defense wall under the changing circumstances of the game, not allowing a shooting gap in the wall. The wide inter-distances in this formation require a fast defense performance and high physical abilities, which the Egyptian team lacked in this championship.

\section{Conclusions}

Within objectives, assumptions and research sample and based on the tools and method used, together with statistical data and treatments, the authors reached the following conclusions:

\section{The ( 6:0 ) defense formation}

- There were (10) combined defense performances in the right and left defense center positions, (12) performances in the right and left back defense positions and (8) performances in the right and left defense wings positions.

- The right defense center position was the most effective position with a success percentage of ( $67.35 \%)$.

- The highest degree of effectiveness in using the (6: 0 ) defense formation occurred in the teams of Croatia and Denmark.

- The low standard of the Egyptian national team in using this formation the team only got the last-butone rank in the team classification.

\section{The (3:2:1) defense formation}

- There were ( 5) combined defense performances in the two front defense centers positions, 4 performances in the back defense center, ( 5 ) performances in the right and left back defense positions and ( 6 ) performances in the right and left defense wings positions.

- The left back defense position was the most effective position with a success percentage of $(68.51 \%)$. 
- The highest degree of effectiveness in using the (3:2:1) defense formation occurred in the teams of Croatia and Slovenia.

- The low standard of the Egyptian national team in using this defense formation. The team got the last rank of effectiveness in the team classification.

Recommendations

The authors recommend the following:

1. Using the composition and integration of combined defense performances of the playing positions, which are similar to actual playing situations in the (6:0) closed formation and the (3:2:1)open formation as used in the World Championship of Spain ( 2013 ), in training programs targeting different age groups.

2. Using as guidelines the training models suggested in Attachment ( 5), in order to upgrade the training process for juniors based on the combined defense performances in the (6:0) closed formation and the (3:2:1) open formation as used in the World Championship of Spain ( 2013).

3. Using as guide the present research paper through the Egyptian handball Federation in order to upgrade the defense performance level of the Egyptian national teams.

\section{References}

\section{$\underline{\text { References in Arabic }}$}

1. Amany Hussein Mohamed (1999): the Effectiveness of Defense Tactics in the Momentary Change of Attack, unpublished thesis for the Master's degree, Faculty of Physical Education for Girls, Alexandria University.

2. Amany Hussein Mohamed (2005): the Mutual Effect of Attack and Defense Tactics on the Effectiveness of Organized Attack in the Finishing Stage in Men's Handball Matches, unpublished thesis for the PH.D degree, Faculty of Physical Education for Girls, Alexandria University.

3. Amr Abdel Fattah Hussein (2009): An Analytical Study of Defense and Attack Tactical Formations as Related to Results of the Matches in the World Championship of Handball (2007) unpublished thesis for the PH.D degree, Faculty of Physical Education, Mansoura University.

4. Amrallah Al Busaty and Mohamed Shawky Keshk (2000): Foundations of Skillful and Tactical Preparation in Football, Dar El Nashr Lel Muallef.

5. Amrallah Al Busaty (1999): An Analytical Study to Identify Components of the Ability to Do a Skillful Performance in Football, Nazaryat wa Tatbikat (Theoris \& Applications), Faculty of Physical Education for Men, Alexandria University.
6. Ekramy Mohamed Abdel Hamid Hamza (2012): An Analytical Study of the Offensive Defense in the Top Level Handball Teams, unpublished thesis for the Master's degree, Faculty of Physical Education for Men, Alexandria University.

7. Galal Kamal Salem (2002): Modern Handball (Foundations and Applications), 1st. edition, Dar Al Fadaeya.

8. Kamal Abdel Hamid Ismail and Mohamed Sobhy Hassanein (2002): the Modern Handball Quartet, Part II, Markaz Al Kitab Lil Nashr, Cairo.

9. Kamal Darwish, Kadry Sayed Morsy and Emad ElDin Abbas (1999): Defense in Handball, Markaz Al Kitab Lil Nashr, Cairo.

10. Marawan Mostafa Ragab (2009): Developing the Speed of Tactical Defense Performances in Handball unpublished thesis for the Master's degree, Faculty of Physical Education for Men, Alexandria University.

11. Medhat Kassem Abdel Razek and Fathy Sadek Mansour (2003): Evaluation of the Effectiveness of Skillful Defensive Performance as Related to Results of Matches Played by Some Teams Participating in Mens' 16th World Cup Championship of Handball, Educational and Sociological Studies Journal, Faculty of Physical Education, Helwan University.

12. Mohamed Abdel Aziz salama (2001): Strategy of Attack and Defense in Basketball, Part $I$.

13. Mohamed Ashraf Kamel (1999): the Effect of a Suggested Program to Develop Some Combined Skillful Performances on the Achievement Level in Under Ten Year Old Handball Juniors, unpublished thesis for the Master's degree, Faculty of Physical Education for Men, Alexandria University.

14. ---.----.-- 2011): the Relationship Between Forms of Combined Defense Movements of the Playing Positions within the 5:1 Formation used by the National Team of France as Guidelines for the Tactical Training of Juniors- an Analytical Study Extracted from the Croatia Handball World Championship (2009).

15. Mohamed Khaled Hammouda and Galal Salem (2008): Attack and Defense in Handball, 1st edition, Max Group, Alexandria.

16. Mounir Guirgis (2004): Handball for All.. Comprehensive Training and Skillful Excellence, Dar Al Fikr Al Araby, Cairo.

17. Tarek Mohamed Salem Rehab (2008): the Effectiveness of Fast Breaks by the Egyptian National Team and the First Four Winners in the Men's World Championships of Handball from 1997 to 2007, unpublished thesis for the PH.D 
degree, Faculty of Physical Education for Girls, Alexandria University.

18. Verner vick, Heins Bosch, Gerd Fischer and Raymon Koch (1997), Applied Practice of Handball, translated by Kamal Abdel Hamid, revised by Mohamed Hassan Allawy, 2nd edition,Dar Al Fikr Al Araby, Cairo.

19. Wafaa Abdel Meguid (2005):Planning a Training Program to Develop the Effectiveness of Some Defensive Tactical Performance Requirements against Fast Breaks in Handball, unpublished thesis for the PH.D degree, Faculty of Physical Education for Girls, Alexandria University.

20. Yasser Mohamed Hassan Dabbour (1996): Training in Handball, Monshaat Al Maaref, Alexandria.

21. (1997): Modern Handball, Monshaat Al Maaref, Alexandria.

22. (2001): Productivity of Offensive Tactical Styles and Defense Formations of the Egyptian National Team and Some International Teams in Handball Matches in France World Cup, Nazaryat wa Tatbikat (Theoris \& Applications), Faculty of Physical Education for Men, Alexandria University. No 43.

\section{References in English}

23. Dietrich Spat (2009): offensive defense the feature of 2008 Olympics, the IHF Technical Magazine.
24. Dietrich Spat (2011): Trends becoming standards overview of the 2011 men's world championship, the IHF technical magazine.

25. Frantisek tabrsky(1999): the method of Quantitative Evaluation of Game performance in handball, special supplement to world handball magazine, Portugal, 1/1999.

26. Frantisek tabrsky, Klause Feldman (2010):Analysis of the 2010 women junior world championship in korea, the IHF, the IHF technical magazine

27. Hagen Rueckner (1999): Basic Tactics in playing handball. www.hagen,rueckner, http:// mitglied. Lycos.de/harueckner/hpdeep.htm.

28. Ike Hufman (2009): analaize wing player

29. Pant Johanson, Frantisek taborsky \& Dietrich Spat (2009): Analysis of world championship for men's handball crootia,2009.the technical magazine.

30. Raphael, Wt (2000): women's coaches seminar, EMF, August 31st-September 2nd.

31. Yasar Savim \& Murat Bilge (2007): The comparison of the last Olympic, world and European men handball championships and the current de.

32. Zoran Valdevit, Zoran Ivic \& Vojislav Malesevic (2004): Qualitative analysis of the 2004 men's 18 european handball championship, Belgrade, Serbia, Montengro, 23-7-2004: 1-8-2004. 